\title{
Vaccine Antagonism in COVID-19 Pandemic: An Appraisal of Statistics and Foundations
}

Saeed Shoja Shafti*

Professor of Psychiatry, University of Social Welfare and Rehabilitation Sciences (USWR), Razi Psychiatric Hospital, Tehran - Iran.

Corresponding author: Saeed Shoja Shafti, Professor of Psychiatry, University of Social Welfare and Rehabilitation Sciences (USWR), Razi Psychiatric Hospital, Tehran - Iran.

Received Date: May 08, 2021; Accepted Date: May 20, 2021; Published Date: June 01,2021

Citation: Saeed S. Shafti (2021). Vaccine Antagonism in COVID-19 Pandemic: An Appraisal of Statistics and Foundations. J Clinical Research and Reports, 8(1); DOI:10.31579/2690-1919/171

Copyright: () 2021 Saeed Shoja Shafti, This is an open access article distributed under the Creative Commons Attribution License, which permits unrestricted use, distribution, and reproduction in any medium, provided the original work is properly cited.

\begin{abstract}
Non-adherence to medical managements or non-compliance with standard shielding maneuvers is a familiar topic in the field of medicine. But now, after delivery of trustable vaccines, though in different brands, refusal of some people, due to personal alibis, to take part actively in vaccination programs against the dominant pandemic of SARS-CoV-2, and energetic encouragement of others to take the same antagonistic attitude, while immunization is the first-line strategy for controlling and preventing the aforementioned sickness, has augmented the said problem, especially when the delivered vaccines are not unreachable for them. Such an attitude, though not prevalent, may be considered as an intruding factor during implementing community vaccination, and if remains unanswered, may delay in some way the desired national outcomes. In the present article the said quandary, along with the plausible psychodynamic, psychopathologic, cultural or administrative causes, as well as available proofs and statistics, has been discussed, concisely.
\end{abstract}

Keywords: COVID-19; SARS-CoV-2; pandemic; vaccine; vaccination; immunization; antipathy; culturable virus; megalo-organisms

\section{Introduction:}

While in another article, the problem of non-adherence to standard shielding maneuvers, whether individually or publicly, has been discussed [1], and in other paper the analogous non-compliance in proficient staffs [2], too, has been talked over, which are, principally, problems in the realm of primary prevention, now another similar confrontation is noticeable, which is over again in the said phase of prevention: that is, rejection of some people, due to personal alibis, to participate actively in immunization programs against the dominant pandemic of SARS-CoV-2 (COVID-19), and energetic encouragement of others to take the same antagonistic attitude, while it is the first-line strategy for controlling and preventing the said sickness. Such an attitude, though not prevalent, may be considered as an intruding factor during implementing community vaccination, and if remains unanswered, may delay in some way the desired national outcomes. In the present article the said dilemma, along with plausible conscious or unconscious reasons, besides current state of affairs and statistics, will be discussed, briefly.

\section{Background:}

Severe acute respiratory syndrome coronavirus 2 (SARS-CoV-2) is primarily spread through saliva droplets, and lengthy physical nearness is considered the main risk factor for contagion. The germ may affect infected persons differently according to preconditions and age. Hence, there is an increased risk of hospitalization, admission to intensive care units (ICU) and decease due to increased age and for those with certain underlying illnesses [3, 4]. It is estimated that up to one-third of the Europeans is either elderly or has one of the underlying disorders, such as chronic respiratory disease, diabetes, hypertension, cardiovascular disease, malignancies, liver disease, certain neurological diseases Down syndrome, and debilitated immune systems, which are associated with risk of severe infection from SARS-CoV-2 [4]. Other issues, such as smoking and obesity, have likewise been noticed to be related with risk of severe sickness from SARS-CoV-2 [5, 6]. Inoculation against SARSCoV-2 is presently being executed worldwide to control the current pandemic. Nonetheless, there are yet queries about the precise nature of safety offered by the different vaccines presently in use and those still in progress. Two of those important inquiries are whether the vaccines A) prevent infection, and B) block transmission. Preventing contagion denotes to a vaccine preventing an inoculated person from getting septic even if they are exposed to the infection. Blocking spread mentions to the vaccine preventing an immunized person who gets infected with the virus from communicating it to other persons [7]. Without a healing treatment or a vaccine, non-pharmaceutical interventions (NPI), such as physical distancing, have been used to reduce the illness. Nevertheless, there are worries about the long-standing sustainability of compliance with such defensive rules in terms of population acceptance and obedience, in addition to the impending societal and financial disadvantages. Therefore, along with NPIs, the development and usage of innocuous and operative vaccines against SARS-CoV-2 is considered the most favorable alternative for controlling the contagion in the long-term. An extraordinary number of vaccine nominees against a single disease and 
with different physiognomies are presently under development. These vaccines are being settled using various high-tech stages, both those previously established and new ones, such as mRNA vaccines [8]. The SARS-CoV-2 epidemic highpoints, once more, the susceptibility of human being to new contagions and immunization remains a conceivable scheme to return to ordinary life [9]. Also, with regard to surveillance objectives, generally the efficiency of SARS-CoV2 vaccines will be examined against: virologically approved symptomatic illness using PCR, laboratory sanctioned infection (symptomatic or asymptomatic) using PCR, or by indicating seroconversion caused by infection, indications of infectiousness and transmissibility - viral load (CT value) and culturable virus, hospitalization, mortality, and straight on person to person spread [10].

\section{Evidential Analysis of Vaccination:}

A number of studies have been published that give answers to queries about effectiveness of vaccination against COVID-19, which have been summarized in Table 1 .

\begin{tabular}{|c|c|c|}
\hline Studies & Year & Conclusion \\
\hline Moghadas et al. ${ }^{11}$ & 2021 & vaccination can have a substantial impact on mitigating COVID-19 outbreaks \\
\hline Vilches et al. ${ }^{12}$ & 2021 & Vaccination can substantially mitigate ongoing COVID-19 outbreaks \\
\hline Patel et al. ${ }^{13}$ & 2021 & $\begin{array}{l}\text { high vaccination coverage, along with continued adherence to non-pharmaceutical interventions, can } \\
\text { contribute to a large reduction in risk of SARS-CoV-2 infection }\end{array}$ \\
\hline Moghadas et al. ${ }^{14}$ & 2021 & $\begin{array}{l}\text { emphasizing the importance of quantifying the durability of vaccine-induced protection after the first } \\
\text { dose as well as vaccine efficacy against infection in order to determine the optimal time interval between } \\
\text { the two doses }\end{array}$ \\
\hline Moghadas et al. ${ }^{15}$ & 2020 & $\begin{array}{l}\text { While vaccination can have a substantial impact on reducing disease transmission, with uptake of } 40 \% \\
\text { or less in the population, vaccination is unlikely to completely eliminate the need for non-pharmaceutical } \\
\text { interventions }\end{array}$ \\
\hline Roghani $\mathbf{A}^{16}$ & 2021 & $\begin{array}{l}\text { Vaccination strategy can significantly influence the numbers of patients with COVID-19 in all age groups } \\
\text { and lower hospitalization and death rates just in older age groups. }\end{array}$ \\
\hline Vasileiou et al. ${ }^{17}$ & 2021 & Higher protection against hospitalization \\
\hline Public Health England ${ }^{18}$ & 2021 & $\begin{array}{l}\text { A greater than } 50 \% \text { reduction in symptomatic cases, even in older vaccines; any cases that do occur in } \\
\text { older vaccinated people are around as half as likely to lead to hospitalization and/or death. This suggests } \\
\text { that those that do develop symptomatic COVID-19 infection after vaccination have a less severe } \\
\text { outcomes }\end{array}$ \\
\hline Hall et al. ${ }^{19}$ & 2021 & $\begin{array}{l}\text { Vaccine effectiveness against symptomatic and asymptomatic infection to be } 70 \% \text { ( } 95 \% \text { CI: } 53 \%, 87 \% \text { ) } \\
21 \text { days after the first dose and } 85 \% \text { (95\% CI: } 74 \% \text { - 96\%) } 7 \text { days after the second dose. This study was } \\
\text { conducted when the UK variant (B.1.1.7) predominated SARS-CoV-2 infections in the UK and provides } \\
\text { evidence that the Pfizer/BioNTech vaccine protects against the UK variant }\end{array}$ \\
\hline Amit et al. ${ }^{20}$ & 2021 & $\begin{array}{l}\text { A study of health care workers found that } 1 \text { dose of the Pfizer/BioNTech vaccine resulted in a reduction } \\
\text { of the rate of SARS-CoV-2 infection by } 75 \% 15-28 \text { days after the first dose of vaccination. }\end{array}$ \\
\hline $\begin{array}{l}\text { European Centre for Diseases } \\
\text { Prevention and Control } \\
(\text { ECDC })^{21}\end{array}$ & 2020 & $\begin{array}{l}\text { The highest efficiency in terms of deaths averted is gained from vaccinating adults aged } 80 \text { years and } \\
\text { over, but in terms of life years saved the most efficient strategy is to extend the program to include } \\
\text { younger adults with preconditions; } 50 \% \text { efficacy against infection in all adults, } 95 \% \text { efficacy against } \\
\text { clinical disease }\end{array}$ \\
\hline $\begin{array}{l}\text { National Institute for Public } \\
\text { Health and the Environment } \\
\text { (RIVM) [Netherlands] }{ }^{22}\end{array}$ & 2021 & $\begin{array}{l}\text { While implementing a COVID-19 vaccination program results in fewer cumulative new infections, new } \\
\text { cases, hospital admissions, IC admissions, new deaths, life years lost, and DALYs compared to no } \\
\text { vaccination, the old to young vaccination program resulted in the smallest number of infections, cases, } \\
\text { hospital admissions, IC admissions, deaths, life years lost and DALYs. }\end{array}$ \\
\hline Chodick et al. ${ }^{23}$ & 2021 & Pfizer/BioNTech vaccine had an effectiveness of 51\% against infection 13-24 days after the first dose. \\
\hline Hunter et al. ${ }^{241}$ & 2021 & $\begin{array}{l}\text { A re-analysis of the above data found that by } 24 \text { days after vaccination vaccine effectiveness reached } \\
90 \%\end{array}$ \\
\hline Petter et al. ${ }^{25}$ & 2021 & $\begin{array}{l}\text { Vaccination by Pfizer/BioNTech vaccine reduced viral load by } 1.6 \text { to } 20 \text { times in vaccinated individuals } \\
\text { who tested positive for SARS-CoV-2. }\end{array}$ \\
\hline Levine-Tiefenbrun et al. ${ }^{26}$ & 2021 & $\begin{array}{l}\text { Infections occurring } 12-28 \text { days after vaccination had a } 4 \text {-fold reduction in viral load. These results } \\
\text { suggest that vaccination may reduce viral shedding and contagiousness, which may prevent onward } \\
\text { transmission }\end{array}$ \\
\hline Bernal et al. ${ }^{27}$ & 2021 & $\begin{array}{l}\text { A recent study from the UK estimated vaccine effectiveness against symptomatic COVID-19 to be } \\
\text { approximately } 60-70 \% \text { in individuals aged } 70 \text { and older after the first dose. Vaccine effectiveness } \\
\text { increased to approximately } 85-90 \% \text { after the second dose. }\end{array}$ \\
\hline
\end{tabular}

Table 1. Available studies with optimistic outcomes re vaccination strategy.

\section{Discussion:}

After the recent pandemic of SARS-CoV-2, along with its huge morbidity, mortalities, and worldwide socioeconomic complications, eventually, by the help of science and biotechnology a number of vaccines against COVID-19, although in different varieties, has been delivered, which like their earlier prototypes, wish to challenge and eradicate the present intrusive microorganism and return the existing state of affairs to the pre-pandemic situation. Vaccine, as a well-founded way out and biomedical armament against a germ, which along with its frequent readjustments challenges vulgarly the existing remedies and therapeutic maneuvers, is the solitary implement for performing miracle by the capability of human being; an armament which has been evolved continuously and inexhaustibly through methodical outlook and unbiased practicality. For example, eradication of smallpox in the last century, and substantial decline of incidence of poliomyelitis, mumps, measles, tetanus, diphtheria, varicella, pertussis, 
tuberculosis, hepatitis (type A and B), rabies, influenza, pneumococcal pneumonia, meningococcal meningitis, whether endemically or epidemically, by active immunizations, has changed radically the natural life of human being and so was a manmade phenomenon. For sure, such an upgrading in lifecycle could not be acquired by nagging or grousing; it demanded humanistic scientists, who could challenge the natural disasters open-mindedly and sturdily. But, in spite of general greeting, some people repel inoculation and encourage others to avoid active immunization because they are suspicious of efficacy or safety of available vaccines, and pronounce that maybe it will annihilate the rest of survivors. While watchfulness with respect to existent threats and real vulnerabilities is an understandable and indispensable code for assuring the safety of self and kinsfolk, excessive distress or irrational antipathy destroys the desired wellbeing. What determines the trustworthiness of a blueprint or instrument? At this time, every evidence-based approach that is established on scientific perspective and methodical assessment can be trustable, except when its detriment is clearly and statistically more than its profit. Who differentiates between disadvantage and advantage? Only the scientist can differentiate between disadvantage and advantage, while he or she ought to consider the ethical issues, too. Who determines the moral code of studies? The ethical committee of associated administration can observe principled values, which are, in biomedical studies, in accordance with The 'Declaration of Helsinki and Ethical Principles for Medical Research Involving Human Subjects' [28]. Accordingly, all human procedures are followed in accordance with the fitting standards of the Institutional Ethics Committee (Human Studies) and with the Helsinki Declaration of 1975 , as revised in 2013. Also, the written informed consent is obtained from the participants, who constitute the considered sample size of every study. Thus, particularly in technologically advanced countries, different aspects or dimensions of biomedical investigates are required to be measured systematically. At this instant and with respect to vaccination, the said protocols are typically observed in the best way. As like as the great wars, which demand skilled commanding officers, pandemics, also, demand knowledgeable specialists. Governing contagion demands specific armamentarium. In this regard, vaccine is one of the most vital armaments, which shapes the primary prevention, instead of secondary prevention, which consist of various therapeutic exercises for management or treatment of ailments, or tertiary prevention, which aims to offset the incapacitating aftermath of illnesses. Persons, who, in spite of available proofs and findings (Table 1), while deny actuality or jeopardy of epidemic, reject the significance and inevitability of immunization, and attempt to interrupt folks' trusts by their own awkward presumptions, may not be recognized as merely prejudiced, illiterate or oblivious people. They may be mentally sick, cerebrally debilitated, or civically devious persons, too; concerns which must be appraised knowledgeably and fairly (Tables 2, 3, and 4) $[29,33]$, because they seem like megalo-organisms that collaborate with microorganisms.

\begin{tabular}{|l|}
\hline Image of illness and weakness \\
\hline Negative experience of others in spite of usage \\
\hline Unknown side effects \\
\hline Unconscious illness tendencies \\
\hline Unconscious wish of death \\
\hline Countertransference to governs, supervisors or health staff \\
\hline Unconscious sense of guilt \\
\hline
\end{tabular}

Table 2. Psychodynamic factors that may, unintentionally, prompt antagonism with regard to immunization [29, 30].

\begin{tabular}{|l|}
\hline Paranoid personality traits or disorders \\
\hline Schizotypal personality traits or disorders \\
\hline Antisocial personality traits or disorders \\
\hline Passive - aggressive personality traits or disorders \\
\hline Sadistic -aggressive personality traits or disorders \\
\hline Sadistic - masochistic personality disorder \\
\hline Depressive personality disorder \\
\hline Intellectual disability \\
\hline Borderline intellectual functioning \\
\hline Oppositional defiant disorder \\
\hline Conduct disorder \\
\hline Depression \\
\hline Phobia \\
\hline Bipolar disorder \\
\hline Delusional disorder \\
\hline
\end{tabular}

Table 3 - Psychopathologic factors that may induce skepticism about vaccination [31, 32].

\begin{tabular}{|l|}
\hline Obeying cult's rubrics \\
\hline Inadequacy of robust proof in support of effectiveness of available vaccines \\
\hline Worried about free will and independence \\
\hline $\begin{array}{l}\text { Relying on strange healers, like shamans, faith healers, naturopaths, and witchdoctors, which seem godlike and free from mistakes or limitations of } \\
\text { conventional medicine. }\end{array}$ \\
\hline Inaccessibility to favored brand among available preparations \\
\hline Disbelieve in managerial system of manufacturing and distribution \\
\hline Political or social antagonism \\
\hline Shortage of an all-encompassing nationwide platform \\
\hline
\end{tabular}

Table 4 - Cultural issues that may decline active participation in vaccination programs [33, 34]. 
So, they may be considered as mortal enemy of civilization and humanity. While everybody has right, such as, to eat adequately or waste with hunger, to walk or drive, to get married or prefer bachelorhood, to rent or be a renter, and to choose between different alternatives, nobody have right to do misconduct or persuade or enforce others to commit crime or attempt suicide. For the sake of safety and survival of society, autonomy and free will cannot be infinite. Though such attitudes may sometimes have populist allures, they are not bearable because they are intrinsically chaotic. Persuading others to avoid participation in immunization is equal to endurance of pollution, morbidity and mortality. It is not, for example, similar to antipsychiatry attitudes, which involves a cadenced frolicking with metaphors and suppositions, by unauthorized guys for uninformed laypeople, who have never understood the real meaning of stigma and severe mental illness, and have never gotten the technical hitches of psychiatric rehabilitation [34]. Twisting folks' thoughts in the direction of refusal of vaccination is per se a criminality because it exposes them to risky situation. Anyhow, though inoculation is the foremost tactic for control and prevention of COVID-19, specific shielding methods, such as wearing facemasks, hand cleanliness, social separation, and suitable ventilation are in the same way significant defensive maneuvers to decrease the risk of becoming septic with viral contagion during a pandemic [35-37], up until delivery of enough vaccination in the community and permission by authorized supervisors. According to some studies, while vaccination can have a real impact on reducing disease transmission and adverse clinical outcomes, with uptake of $40 \%$ or less in the population, vaccination is unlikely to eliminate the need for nonpharmaceutical interventions [15]. Undoubtedly, apposite interventions for targeting public misunderstandings about recommended shielding and preventative maneuvers can reduce preventable infection rates during pandemic. No society can stay alive without collective care and concern. Thoughtless demeanor of an inhabitant, thanks to private considers, is not allowed, since prejudice is endless, while fairness has clear boundaries and clues. Converting group favoritism to joint fairness is a stipulation if civic success is a mutual hope. Every citizen must be bright enough to comply with methodical guidelines, scientific discoveries, and logical recommendations, for the sake of public safety; otherwise, nasty microorganisms may find lots of free and undisclosed organic reservoirs for hiding, reproduction, and bullying human civilization; each time more devastating, infective, and lethal than before.

\section{Conclusion:}

Providing public safety is not possible without active participation and mutual group effort of all citizens, particularly through catastrophes and pandemics. So, while personal guardedness or skepticism is in the frame of citizens' rights, propagation of societal cynicism, based on subjective uncertainties and philosophies, does not have anything to do with civil liberties, since it may ruin publics' confidence and well-being seriously and irremediably. Moving from subjective deduction to objective verification could be acknowledged as one of the most important outcomes of cultural - historical evolution of human being. At present, Evidence - Based Medicine (EBM) and systematic biomedical studies can be accepted as trusty screens for escaping unsoundness and partiality, and final choice of favored method among some choices, especially with regard to civic protection. In nationwide misfortunes, individualism cannot be acknowledged as a respectable philosophy if it is devoid of problem - solving, assistant, or alleviating role. According to the available data, community participation in national vaccination programs is the best way for guaranteeing healthier environments and existence.

\section{References:}

1. Shoja Shafti S. (2021) A Systematic Review of Dynamic Forces as Regards Mask Non-Adherence in Healthcare and
Community Settings. Mental Health \& Human Resilience International Journal, 5(1): 000141.

2. Shoja Shafti S. (2020) Necessity of Educational Reconsideration with Reference to Shielding Responsibilities. Scholarly Journal of Psychology and Behavioral Sciences; 4(1): 410-411.

3. Chiappetta S, Sharma AM, Bottino V, Stier C. (2020) COVID19 and the role of chronic inflammation in patients with obesity. Int J Obes (Lond). 2020; 44 (8):1790-1792.

4. Costa FF, Rosario WR, Ribeiro Farias AC, de Souza RG, Duarte Gondim RS, Barroso WA. (2020). Metabolic syndrome and COVID-19: An update on the associated comorbidities and proposed therapies. Diabetes Metab Syndr 2020; 14(5): 809814.

5. European Centre for Disease Prevention and Control (ECDC). High-risk groups for COVID-19. Stockholm: ECDC; 2020.

6. World Health Organisation Europe. Health workers at risk, older adults and residents of long-term care facilities to be prioritized for COVID-19 vaccination. Copenhagen: WHO Euro;

7. National Institute for Public Health and the Environment (RIVM). The expected outcome of COVID-19 vaccination strategies: version 1.0, March 24th, 2021: 1-75.

8. Callaway E. (2020). The race for coronavirus vaccines: a graphical guide. Nature; (7805):576-577.

9. Roghani A. The Influence of Covid-19 Vaccine on Daily Cases, Hospitalization, and Death Rate in Tennessee: A Case Study in the United States. medRxiv

10. Public Health England (PHE). PHE monitoring of the early impact and effectiveness of COVID-19 vaccination in England. 2021: 1-17.

11. Moghadas SM, Vilches TN, Zhang K, et al. (2021). The impact of vaccination on COVID-19 outbreaks in the United States. Clin Infect Disciab079.

12. Patel MD, Rosenstrom E, Ivy JS, Mayorga ME, et al. (2021) The Joint Impact of COVID-19 Vaccination and NonPharmaceutical Interventions on Infections, Hospitalizations, and Mortality: An Agent-Based Simulation medRxiv ; 2020.12.30.20248888.

13. Moghadas SM, Vilches TN, Zhang K, et al. (2021) Evaluation of COVID-19 vaccination strategies with a delayed second dose medRxiv. ; 2021.01.27.21250619.

14. Moghadas SM, Vilches TN, Zhang K, et al. The impact of vaccination on COVID-19 outbreaks in the United States medRxiv. 2020; 2020.11.27.20240051.

15. Roghani A. (2021) The Influence of Covid-19 Vaccine on Daily Cases, Hospitalization, and Death Rate in Tennessee: A Case Study in the United States. medRxiv doi.org/10.1101/2021.03.16.21253767.

16. Vasileiou E, Bradley D, Chuter A, et al.(2021) Effectiveness of First Dose of COVID-19 Vaccines Against Hospital Admissions in Scotland: National Prospective Cohort Study of 5.4 Million People. (THELANCET-D-21-01335). Social Science Research Network (SSRN).

17. Public Health England (PHE). PHE monitoring of the early impact and effectiveness of COVID-19 vaccination in England. 2021: 1-17.

18. Hall VJ, Saei S, Andrews A, et al. Effectiveness of BNT162b2 mRNA Vaccine Against Infection and COVID-19 Vaccine Coverage in Healthcare Workers in England, Multicentre Prospective Cohort Study (the SIREN Study).

19. Amit S, Regev-Yochay G, Afek A, Kreiss Y, Leshem E. (2021) Early rate reductions of SARS-CoV-2 infection and 
COVID-19 in BNT162b2 vaccine recipients. The Lancet; 397(10277): 875-877.

20. European Centre for Disease Prevention and Control. COVID19 vaccination and prioritisation strategies in the EU/EEA. (2020). ECDC: Stockholm; 2020: 1-20.

21. National Institute for Public Health and the Environment (RIVM). The expected outcome of COVID-19 vaccination strategies: version 1.0, March 24th, 2021: 1-75.

22. Chodick G, Tene L, Patalon T, et al. (2021). The effectiveness of the first dose of BNT162b2 vaccine in reducing SARS-CoV2 infection 13-24 days after immunization: real-world evidence. medRxiv 2021: p. 2021.01.27.21250612.

23. Hunter, P.R. and J. Brainard, Estimating the effectiveness of the Pfizer COVID-19 BNT162b2 vaccine after a single dose. A reanalysis of a study of 'real-world' vaccination outcomes from Israel. medRxiv 2021: p. 2021.02.01.21250957.

24. Petter E, Mor O, Zuckerman N, et al. (2021) Initial real world evidence for lower viral load of individuals who have been vaccinated by BNT162b2. medRxiv: p. 2021.02.08.21251329.

25. Levine-Tiefenbrun M, Yelin I, Katz R, et al. (2021) Decreased SARS-CoV-2 viral load following vaccination. medRxiv: p. 2021.02.06.21251283.

26. Bernal JL, Andrews N, Gower C, et al. (2021). Early effectiveness of COVID-19 vaccination with BNT162b2 mRNA vaccine and ChAdOx1 adenovirus vector vaccine on symptomatic disease, hospitalisations and mortality in older adults in England. medRxiv: p. 2021.03.01.21252652.

27. Medical Association Declaration of Helsinki: ethical principles for medical research involving human subjects. JAMA 2013; 310(20): 2191-4.

28. Bush F, Auchincloss EL (1995) The Psychology of Prescribing and Taking Medication in: Schwartz HJ, Bleiberg E, Weissman SH (Eds.), Psychodynamic
29. Concepts in General Psychiatry. American psychiatric press, Inc. Washington DC, (1995): 401-416.

30. Shoja Shafti S (2020) Psychoanalytic Analysis of Psychopathology. 2nd edition, Tehran, Jami Publishing Company, 2020.

31. American Psychiatric Association (APA). Diagnostic and Statistical Manual of Mental Disorders. 5th edition. Washington, DC: American Psychiatric Association,( 2013): 31-708.

32. Harrison P, Geddes J, Sharpe M. (2010)Lecture Notes: Psychiatry. 10th edition, West Sussex, UK: John Wiley \& Sons Ltd.

33. Shoja Shafti S. Narcissism(2020). Groundwork for Sectarian Misdemeanors. Int J Psychiatr Ment Health; 2: 8-16.

34. Sadock BJ, Sadock VA, Ruiz P.(2015) Other Conditions that May be a Focus of Clinical Attention: Cults. KAPLAN \& SADOCK'S Synopsis of Psychiatry. 11th edition, Wolters Kluwer, Philadelphia: 812-823.

35. Shoja Shafti S. (2021) Psychiatric Stigma in Developing Societies. Biomedical Research and Clinical Reviews; 3 (3):15.

36. Zhang C-Q, Chung P-K, Liu J-D , Chan DKC, Hagger MS, Hamilton K. (2019)Health Beliefs of Wearing Facemasks for Influenza A/H1N1 Prevention: A Qualitative Investigation of Hong Kong Older Adults. Asia Pac J Public Health ; 31(3): 246-256.

37. Ma QX, Shan H, Zhang HL, Li GM, Yang RM, Chen JM. Potential utilities of mask-wearing and instant hand hygiene for fighting SARS-CoV-2external icon. J Med Virol 2020; 92(9):1567-1571.

38. Shoja Shafti S. Non-compliance with Wearing Facemasks thru Pandemics: Reappraisal of Interconnected Dynamics. Applied Medical Research 2021; 8 (1): 1- 5.
This work is licensed under Creative Commons Attribution 4.0 License
To Submit Your Article Click Here: Submit Manuscript

DOI: $10.31579 / 2690-1919 / 171$

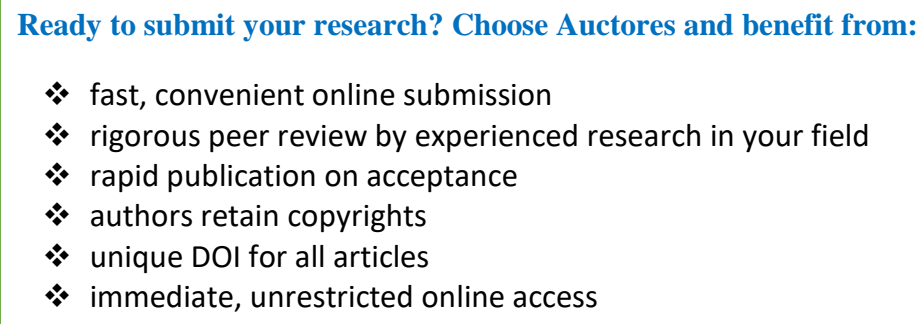

At Auctores, research is always in progress.

Learn more www.auctoresonline.org/journals/journal-of-clinicalresearch-and-reports 